\title{
The natural history of greater trochanteric pain syndrome: an 11-year follow-up study
}

Luke Bicket ${ }^{1}$, Julie Cooke ${ }^{1,2}$, Isaac Knott ${ }^{4}$ and Angie Fearon 1,2,3*

\begin{abstract}
Background: Greater trochanteric pain syndrome (GTPS) is a musculoskeletal condition which can cause disability and reduce quality of life. However, limited evidence is available on the long-term outcomes of people with GTPS. Our aims were to determine the long-term prevalence of GTPS; to calculate the proportion of people with GTPS who had developed hip osteoarthritis (OA); and to determine the level of function and quality of life, 11-years after initial GTPS diagnosis.

Methods: A prospective 11-year natural history study. Two groups [GTPS group $(n=24)$, asymptomatic control (ASC) group $(n=20)$ ] were evaluated at baseline, 12-months and 11-years. At 11-years all participants completed the modified Harris Hip Score (mHHS), Oswestry Disability Index (ODI) and Assessment of Quality-of-Life questionnaire. At 11 -year follow-up 20/24 GTPS and 19/20 ASC participants were clinically assessed for GTPS and hip OA, completed the 10 metre-walk-test, timed up and go, and hip abduction and external rotation strength testing.

Results: At 11 -year follow-up 45.0\% of GTPS participants had GTPS compared to $5.3 \%$ of ASC participants ( $p=0.008$ ), OR [95\% CI]: $10.19[1.95,104.3]$, and 35.0\% of GTPS participants were clinically diagnosed with hip OA compared to none of the ASC participants ( $p=0.002$ ), OR [95\% Cl]: 21.6, $[2.3,2898.0]$. GTPS participants reported more pain and disability than ASC participants via the ODI, mean difference [95\% CI]: 6.1 [0.7, 11.6] but not the modified Harris Hip Score, mean difference $[95 \% \mathrm{CI}]:-3.3[-10.3,3.7]$. Both groups had similar levels of quality of life and measures of function.
\end{abstract}

Conclusions: GTPS is a chronic condition: people with GTPS at baseline had twice the odds of being clinically diagnosed with GTPS or hip OA than the control group at 11-years. Further, there appears to be a temporal relationship between GTPS and the development of hip OA. This finding highlights the need to identify effective treatments that address the underlying impairments associated with GTPS. Pain and function results varied depending on the assessment tools used. Between group differences in quality of life seen at baseline are not found at the 11-year follow-up. The small sample size means the results must be considered with caution.

Level of Evidence: Level II Natural history Study.

Keywords: Greater trochanteric pain syndrome, GTPS, hip osteoarthritis, Hip OA, hip pain, bursitis, Gluteal tendinopathy, Trochanteric bursitis, follow-up, natural history

*Correspondence: Angie.Fearon@canberra.edu.au

${ }^{2}$ Research Institute for Sport and Exercise, University of Canberra, 11 Kirinari St, Bruce, ACT 2617, Australia

Full list of author information is available at the end of the article

\section{Background}

Greater trochanteric pain syndrome (GTPS) causes pain on the lateral side of the hip with subsequent dysfunction which negatively impacts quality of life and reduces the ability to remain in full-time work, compared to healthy age matched controls [1]. The underlying pathology is thought original author(s) and the source, provide a link to the Creative Commons licence, and indicate if changes were made. The images or other third party material in this article are included in the article's Creative Commons licence, unless indicated otherwise in a credit line to the material. If material is not included in the article's Creative Commons licence and your intended use is not permitted by statutory regulation or exceeds the permitted use, you will need to obtain permission directly from the copyright holder. To view a copy of this licence, visit http://creativecommons.org/licenses/by/4.0/. The Creative Commons Public Domain Dedication waiver (http://creativeco mmons.org/publicdomain/zero/1.0/) applies to the data made available in this article, unless otherwise stated in a credit line to the data. 
to primarily be due to gluteus medius and gluteus minimus tendinopathy $[2,3]$. GTPS is more common than Achilles tendinopathy, with a prevalence of $4.22 / 1000$ person-years, and an incidence rate of 3.29/1000 person-years [4], yet there is little long-term data about this condition.

The single prognostic study on GTPS $(n=164)$ reported at least $36 \%$ of people at 1 -year and $29 \%$ of people at 5 -years post diagnosis still had GTPS, with $24 \%$ self-reporting concurrent hip osteoarthritis (OA) [5]. While informative, this primary care, GP based study was limited by the low follow-up rate (54\%), the retrospective design, lack of a clinical interview or examination to confirm the diagnosis and the absence of imaging findings at any point in the study. To our knowledge there is no long-term study that reports on dysfunction, quality of life or function in people with GTPS.

GTPS has been linked to end-stage hip OA [6-8]. The incidence of gluteal tendon tears, likely severe GTPS [1], identified at hip arthroplasty ranges from $1.6 \%$ [6] to $20 \%$ [7], suggesting a mild to moderate association between GTPS and end-stage hip OA. However, there are no longitudinal studies to indicate if the conditions arise concurrently or sequentially. A clearer understanding of the relationship between GTPS and hip OA is important for further research into the treatment of GTPS and consequently patient management.

The dysfunction and quality of life of people with GTPS, and those with gluteal tendon tears has been shown to be poor compared to an aged and sex matched asymptomatic control group, and similar to people with end stage hip OA $[1,9]$. To our knowledge, there are no longitudinal studies that have examined if these finding persist over time.

In summary, there is a lack of evidence surrounding the long-term outcomes of GTPS and potential associations with ongoing GTPS and hip OA. Therefore, our research questions were:

1. What is the GTPS status of a GTPS cohort and an asymptomatic control cohort at 11-years follow-up?

2. What is the hip OA status of a GTPS cohort and an asymptomatic control cohort at 11-years follow-up?

3. What are the comparative (disability, quality of life and clinical function) outcomes of people with GTPS and an asymptomatic control cohort at one and 11 -years following initial assessment for GTPS?

\section{Methods}

\section{Study design and setting}

This prospective cohort study was completed in a university setting at three time points: baseline (2008), 12-months (2009), and 11-years (2019). Between baseline and 12-month follow-up participants received intermittent (approximately second monthly) correspondence with the aim of reducing attrition. This study was approved by university human research ethics committees (HREC: 20181528), all participants provided informed consent. Previous consent had been obtained from the participants at the baseline assessment for later follow-up, all participants reconsented for the 2019 follow-up assessment.

\section{Participants}

A total of 85 participants were originally recruited from the local community via professional networks and wordof-mouth between March 2008 and November 2009. The initial sample included three mutually exclusive groups, a GTPS group ( $n=42,11$ of whom underwent gluteal reconstruction surgery in the following 12 months), a hip OA group $(n=20$, all who underwent total hip arthroplasty (THA) in the following 12 months), and an asymptomatic control group (ASC) $(n=23)$ of similar age and sex to the GTPS participants. This 11-year follow-up study reviews a subset of the original cohort, see exclusion criteria for the 11-year follow-up study.

Inclusion criteria for this study (11-year follow-up) was having previously been involved in the GTPS study of 11-years ago $[1,10]$. Relevant inclusion criteria for the baseline study were being over 18-years of age, able to communicate in English and a) GTPS group: having a clinical diagnosis of GTPS (minimum three-month history of lateral hip pain, pain on palpation of the greater trochanter, and pain with either lying on the hip during weight bearing, or sitting), or b) asymptomatic control group (ASC): having no history of lower limb injury or disease. Exclusion criteria at baseline for both groups were evidence of intra-articular hip joint pathology (clinically: reporting groin pain, groin pain with any hip examination test (e.g. FADDIR/FABER/internal rotation) and on imaging (x-ray or MRI)), systemic inflammatory disease, a history of hip or spinal surgery, for the GTPS group a cortisone injection into the lateral hip within the last 3 months and for the ASC group any history of hip pain $[1,10]$.

Exclusion criteria for the 11-year follow-up study were participants from the original cohort who underwent surgery in the 12 months following baseline assessment, (gluteal tendon reconstructive surgery $(n=11)$ or THA $(n=20))$.

We attempted to contact all remaining participants $(n=54)$, regardless of their symptomatic status, to invite to take part in this 11-year follow-up study. For clarity we have continued to use the descriptors GTPS and ASC for the groups regardless of their current diagnosis. Following email, postal mail, phone calls and checking the electoral roll we were unable to contact five 


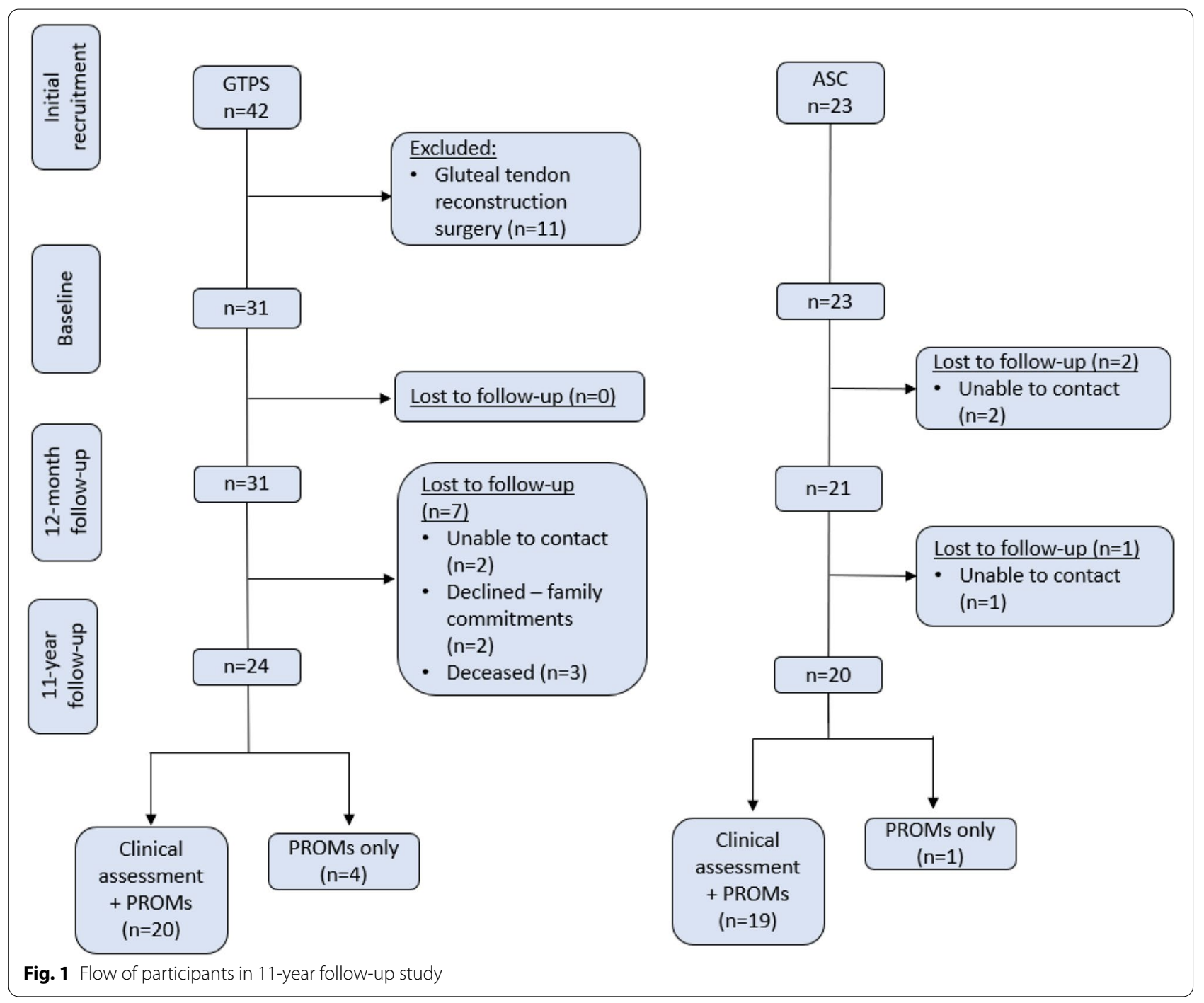

previous participants (two GTPS and three ASC), we were informed that three GTPS participants had passed away, and two GTPS participants declined to be involved, leaving GTPS $n=24$, ASC $n=20$ (Fig. 1).

All the 11-year follow-up assessments were performed by a successfully blinded assessor (LB), a final year physiotherapy student, trained and supervised in the assessment techniques by the senior author who has 20 years of clinical experience in diagnosing hip conditions (AF).

\section{Participant demographic details}

Participant age, sex, weight, height, receipt of corticosteroid injections, and employment status were recorded as these have previously been associated with GTPS [1, 8] and may have been co-variants during data analysis. At baseline, the most affected leg was chosen as the index leg for the GTPS group. All data presented in this study including patient reported and clinical examination results relate to the index leg. For the ASC group the "index leg" was randomly assigned as baseline analysis found no between leg hip abduction strength difference $(\operatorname{ICC}(C, 1)(95 \% \mathrm{CI})=0.86(0.70$ to 0.94$))$. Data from the same leg is reported for each data collection point.

\section{Clinical diagnosis}

To determine the clinical diagnosis of GTPS at 11-years follow-up we used the same criteria as at baseline: a minimum three-month history of lateral hip pain, pain on palpation of the greater trochanter, and pain with either lying on the hip, during weight bearing, or sitting [1].

To determine the clinical diagnosis of hip OA we used Altman (1991) criteria: history of hip pain and internal rotation $<15^{\circ}$ and flexion $<115^{\circ}$, or a history of hip pain, pain on internal rotation, morning stiffness $\leq 60$ minutes, 
and age $>50$ years [11]. Where measures were close to these cut off $\left(<15^{\circ}\right.$ of internal rotation in $90^{\circ}$ flexion, or $<115^{\circ}$ flexion in supine) a goniometer was used to measure the range. Alternatively, a history of total hip arthroplasty for hip OA on the affected side was considered a diagnosis of hip OA [12]. Following the publication of a recent systematic review on clinically diagnosing hip OA [13], we undertook a post-hoc determination of hip OA diagnosis based on our existing data (Additional file 1). Where a person presented at 11-year follow-up with groin or lateral hip pain but did not fit the Altman criteria, they were categorised as having "other source of hip pain".

\section{Disability and quality of life}

In the absence of a condition specific measure for this population at baseline, measures with face validity were used. To enable a longitudinal comparison, we chose to repeat those measures at the 11-year follow-up.

As per the baseline $[1,10]$, we assessed:

- quality of life with the Assessment of Quality of Life questionnaire (AQoL 4-D [14, 15])

- disability via the modified Harris Hip Score (mHHS) [16] and the Oswestry Disability Index (ODI) [17]. For the ODI, participants were asked to respond in relation to their leg pain, rather than any existing back pain.

- the number of co-morbidities via the Functional Comorbidities Index (FCI) [18]

\section{Functional outcomes}

As per the baseline, four reliable and valid clinical tests were undertaken by LB. As noted above LB was trained and supervised by AF.

- Hip abduction and external rotation strength, normalised to mass ( $\mathrm{kgf} / \mathrm{m}^{\text {BMavg }}$ ) [19]

- Gait speed via the 10 -meter walk test $(10 \mathrm{mwt})(\mathrm{m} / \mathrm{s})$ [20]

- $\quad$ Timed up and go (TUG) (s) [21]

Maximum isometric hip abduction (in supine) and external rotation strength (in prone) were assessed using the same fixed calibrated hand-held dynamometer, (Chatillon, MSC FL, USA) as used at baseline assessment" [10]. The 10mwt was completed four times with participants instructed to walk at a "fast and safe pace" and to start on "ready, set, go!". The TUG was performed in the standard manner, however the instructions were inadvertently varied from the original study [10]. At each time point, the average of these measures is reported.

\section{Sample size calculation}

In this natural history study, we attempted to contact all eligible previous participants from the baseline exploratory study $[1,10]$ via email, letters, phone calls and a search on the Australian electoral role, thus no sample size calculation was undertaken.

\section{Statistical analysis}

The baseline and 12-month data from the two surgical groups were not included in the 11-year follow-up analysis. Data were visually assessed for normality and found to be skewed. Demographic measures are presented using median and interquartile ranges (IQR). For continuous data, between group differences were examined using independent-samples Mann-Whitney $\mathrm{U}$ tests. For categorical data (sex, obesity, number of cortisone injections and full-time work status), Chisquare $\left(X^{2}\right)$ analysis was undertaken, except where cell frequency was less than five, when a Fisher Exact test was implemented.

To account for body size effect on hip strength, strength data was standardised to participant body mass via the body mass average index (BMavg) [19].

To answer question 1 and 2, we undertook Fisher Exact evaluations. The post-hoc analysis of the alternative method to diagnose hip OA did not change the overall outcome (Additional file 1), thus we report using the Altman criteria [11]. The Odds Ratio (OR) [95\%CI] of having GTPS, or developing hip OA were calculated post hoc using 'penalized logistic regression (Firth method [22]) as implemented in $\mathrm{R}$ package 'logistf' [23] , with confidence intervals from the profile likelihood [24].

To answer question 3, we built linear mixed models with group as the fixed effect and age and co-morbidities (FCI) as co-variates at each time point, having found work-status and the number of cortico-steroid injections that a participant reported did not alter outcomes. The results are reported as estimated marginal means (EMM), standard error of the mean (SEM), differences between group means and 95\% confidence intervals. SPSS version 22.0 (IBM Corp. Released 2017.Version 25.0. Armonk, NY) was used for all statistical analyses, except for the odds ratio, which was calculated using R (RStudio Team (2020). RStudio: Integrated Development for R. RStudio, PBC, Boston, MA URL http://www.rstudio.com/). Significance level was set at $p<0.05$. 


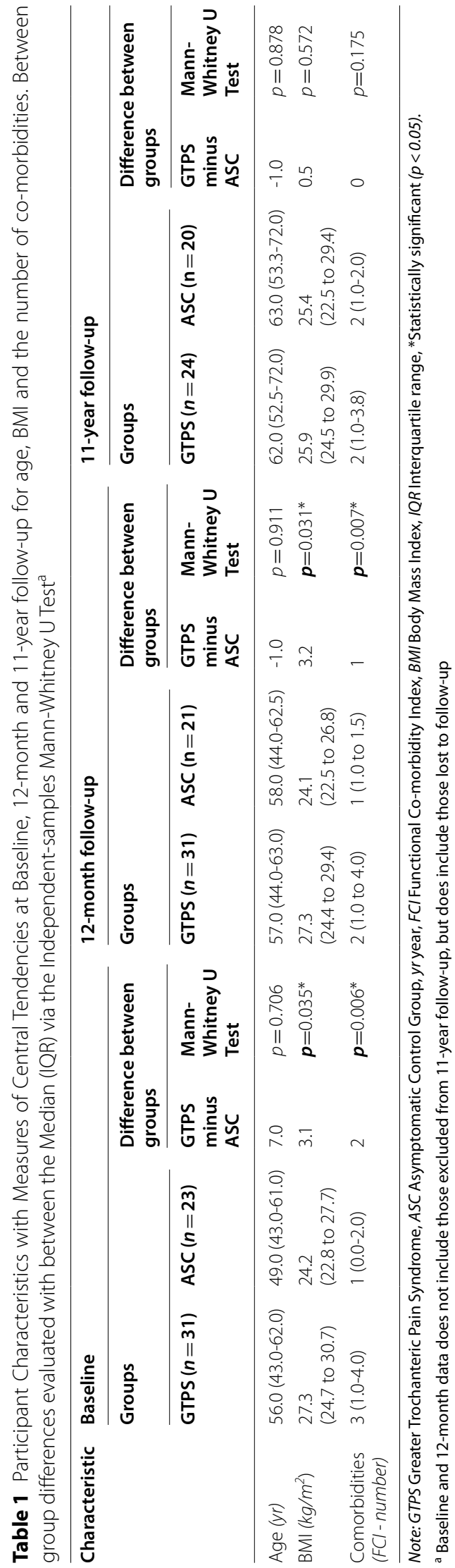




\section{Results}

\section{Demographics}

We recruited 44 (GTPS $=24$, ASC $=20)$ of the 54 eligible past participants. We clinically assessed 20 (64.5\%) and recorded patient reported outcomes for 24 (77.4\%) of eligible GTPS participants. We clinically assessed 19 (82.6\%) and recorded patient reported outcomes for 20 (86.9\%) of eligible ASC participants. A total of five participants could not attend the clinical examination due to living interstate, or carers duties prohibiting their attendance (Fig. 1). Participants were matched for age and sex at baseline and had comparable age and sex at subsequent assessments. Group differences were seen for BMI, but not obesity. GTPS participants had more co-morbidities than the ASC group at baseline and at 12-month followup, but not at the 11-year follow-up, Table 1. The GTPS group had more corticosteroid injections and more hip arthroplasties, while full-time work status varied across the years, Table 2 .

\section{Outcomes}

At 11-year follow-up a larger proportion of GTPS participants had a clinical diagnosis of GTPS than the ASC participants, (Fisher exact, $p=0.008$ ), OR [95\% CI]: 10.19 $[1.95,104.3]$. A large proportion of GTPS participants had gone on to develop hip OA, while none of the ASC had gone on to develop hip OA according to Altman's criteria (Fisher exact, $p=0.002$ ), OR $[95 \% \mathrm{CI}]=21.6$ [2.30, 2898.0]. 18.2\% of the GTPS had both GTPS and hip OA, while close to $80 \%$ of the ASC remained free of hip pain, Fig. 2.

\section{Patient reported and functional outcomes at 12-months and 11-years}

GTPS participants had a lower quality of life than ASC participants at baseline $(p=0.004)$. This difference was not present at 12-months, or at 11-years. GTPS participants reported more disability on the mHHS and the ODI at baseline and 12-months, $(p<0.04)$ and on the ODI (but not the mHHS) at 11 -years $(p=0.028)$, Table 2.

There was no group difference for hip abductor or external rotator strength at baseline or 12-month followup. The GTPS group had weaker hip abduction than the ASC at 11 -years follow-up $(p=0.032)$. The GTPS group walked more slowly at baseline (gait speed, $p<0.001$ ) than the ASC, and were slower on the TUG at the 11-year follow-up than the ASC, Table 2.

\section{Discussion}

In this cohort, people with GTPS were more likely to continue to experience hip pain 11-years after baseline assessment when compared to an ASC group. Further, a significantly higher proportion of people with GTPS went on to develop hip OA, than the ASC group. We also found that many of the dysfunctions, quality of life and functional outcome differences seen at baseline between the GTPS and ASC groups had diminished, or no longer existed, at 11-years follow-up (Table 3).

Hip pain is a common cause of pain and disability in older people [25]. Our findings support and extend the findings of Lievense (2005) [5] who, in a retrospective questionnaire based study found $29 \%$ of participants continued to report GTPS symptoms, with $24 \%$ reporting both GTPS and hip OA diagnosis at five years follow-up. As no clinical assessment was reported for their baseline or follow-up data, it is not clear if the hip OA existed at baseline, or if a higher proportion of their cohort may have had hip OA. In contrast our prospectively collected data showed our participants had no clinical or imaging evidence of intra-articular hip joint pathology at baseline. The increased rate of hip OA in our cohort is likely explained by the longer follow-up period, allowing a longer duration for hip OA to develop.

Our findings support a temporal association between GTPS and hip OA which has not previously been identified, meaning that a clinical diagnosis of GTPS likely results in a higher chance of developing symptomatic hip OA. In 60-64 year old people the estimated prevalence of radiological diagnosis of hip OA ranges from 0.5\%-11.5\% [26]. Our GTPS participants demonstrated a much higher rate than this. Associations between tendon degeneration and OA have previously been identified at the shoulder [27], between hip OA and obturator internus tendinosis [28], and between the gluteal tendon tears in those undergoing hip arthroplasty surgery $[6,7]$. It has been hypothesised that the increased hip adductor moment seen in people with GTPS puts greater load on the gluteal tendons resulting in the persistence of GTPS [29] and similarly, increases the load within the joint [30], possibly contributing to the development of hip OA. Gluteus medius and minimus muscles contribute to stabilising the head of femur within the acetabulum whilst walking [31]. Thus, pathology of this muscular tendinous complex may contribute to, or precede the development of hip OA. We note that our two groups had no difference in strength so other factors such as motor control or somatosensory impairments may also be contributing factors. There is a small amount of evidence suggesting that individuals with GTPS have somatosensory impairments [32, 33], which could contribute to the development of hip OA. Thus, addressing this issue early may be beneficial.

The baseline higher levels of disability and lower quality of life seen in people with GTPS compared to controls were not consistently found at the 11-year 
Table 2 Participant Characteristics for sex, obesity, number of corticosteroid injections and hip arthroplasty surgery. Number (\%), evaluated using $X^{2}$ or Fisher Exact Test ${ }^{a}$

\begin{tabular}{|c|c|c|c|c|c|c|c|c|c|}
\hline \multirow[t]{3}{*}{ Characteristic } & \multicolumn{3}{|l|}{ Baseline } & \multicolumn{3}{|c|}{ 12-month follow-up } & \multicolumn{3}{|c|}{ 11-year follow-up } \\
\hline & \multicolumn{2}{|l|}{ Groups } & \multirow{2}{*}{$\begin{array}{l}\text { GTPS vs ASC } \\
X^{2} / \text { Fischer } \\
\text { exact }\end{array}$} & \multicolumn{2}{|l|}{ Groups } & \multirow{2}{*}{$\begin{array}{l}\text { GTPS vs ASC } \\
X^{2} / \text { Fischer } \\
\text { exact }\end{array}$} & \multicolumn{2}{|l|}{ Groups } & \multirow{2}{*}{$\begin{array}{l}\text { GTPS vs ASC } \\
X^{2} / \text { Fischer } \\
\text { exact }\end{array}$} \\
\hline & $\begin{array}{l}\text { GTPS } \\
(n=31)\end{array}$ & $\begin{array}{l}\text { ASC } \\
(n=23)\end{array}$ & & $\begin{array}{l}\text { GTPS } \\
(n=31)\end{array}$ & $\begin{array}{l}\text { ASC } \\
(n=21)\end{array}$ & & $\begin{array}{l}\text { GTPS } \\
(n=24)\end{array}$ & $\begin{array}{l}\text { ASC } \\
(n=20)\end{array}$ & \\
\hline Female, & $28(90.3)$ & $22(95.7)$ & $p=0.628$ & $28(90.3)$ & $20(95.2)$ & $p=0.639$ & $22(91.7)$ & $19(95.0)$ & $p=1.000$ \\
\hline $\begin{array}{l}\text { Obese (BMI } \geq \\
\text { 30.0), }\end{array}$ & $9(29.0)$ & $2(8.7)$ & $p=0.092$ & $6(19.4)$ & $0(0.0)$ & $p=0.070$ & $5(20.8)$ & $4(20.0)$ & $p=1.000$ \\
\hline $\begin{array}{l}\text { People who } \\
\text { had had a CSI } \\
\text { (cumulative } \\
\text { number (\%)) }\end{array}$ & $7(22.6)$ & $0(0.0)$ & $p=0.015^{*}$ & $14(45.2)$ & $0(0.0)$ & $\boldsymbol{p}<0.001^{*}$ & $17(70.8)$ & $1(5.0)$ & $\boldsymbol{p}<0.001^{*}$ \\
\hline Full-time work, & $13(41.9)$ & $16(69.6)$ & $p=0.057$ & $10(32.3)$ & $13(61.9)$ & $p=0.048^{*}$ & $6(25.0)$ & $7(35.0)$ & $p=0.522$ \\
\hline $\begin{array}{l}\text { THA on } \\
\text { affected leg } \\
\text { (Number (\%)) }\end{array}$ & 0 & 0 & & 0 & 0 & & $\begin{array}{l}4 \\
(16.7)\end{array}$ & 0 & \\
\hline
\end{tabular}

Note: GTPS Greater trochanteric pain syndrome; Where cell values were less than 5 Fisher Exact tests was used. *Statistically significant $(p<0.05)$.

CSI Corticosteroid injection - numbers carried forwards.

a Baseline and 12-month data does not include those excluded from 11-year follow-up, but does include those lost to follow-up

follow-up. At the 12-month follow-up, our GTPS cohort reported apparent improvements in quality of life. Further, at this time there appeared to be a smaller between group difference in the disability scores (mHHS and ODI). By 11-years, only the ODI continued to have a (small) between group difference, noting that ODI has been found to measure a different construct than the subsequently developed condition specific VISA-G [34]. The changes after 12-months in the GTPS participants may be due to the Hawthorne effect [35]. The lack of between group difference seen at 11-year years may be due, in part, to the increased rate of hip pain $(\sim 20 \%)$, in the ASC group which did not exist at baseline, and the increased number of comorbidities

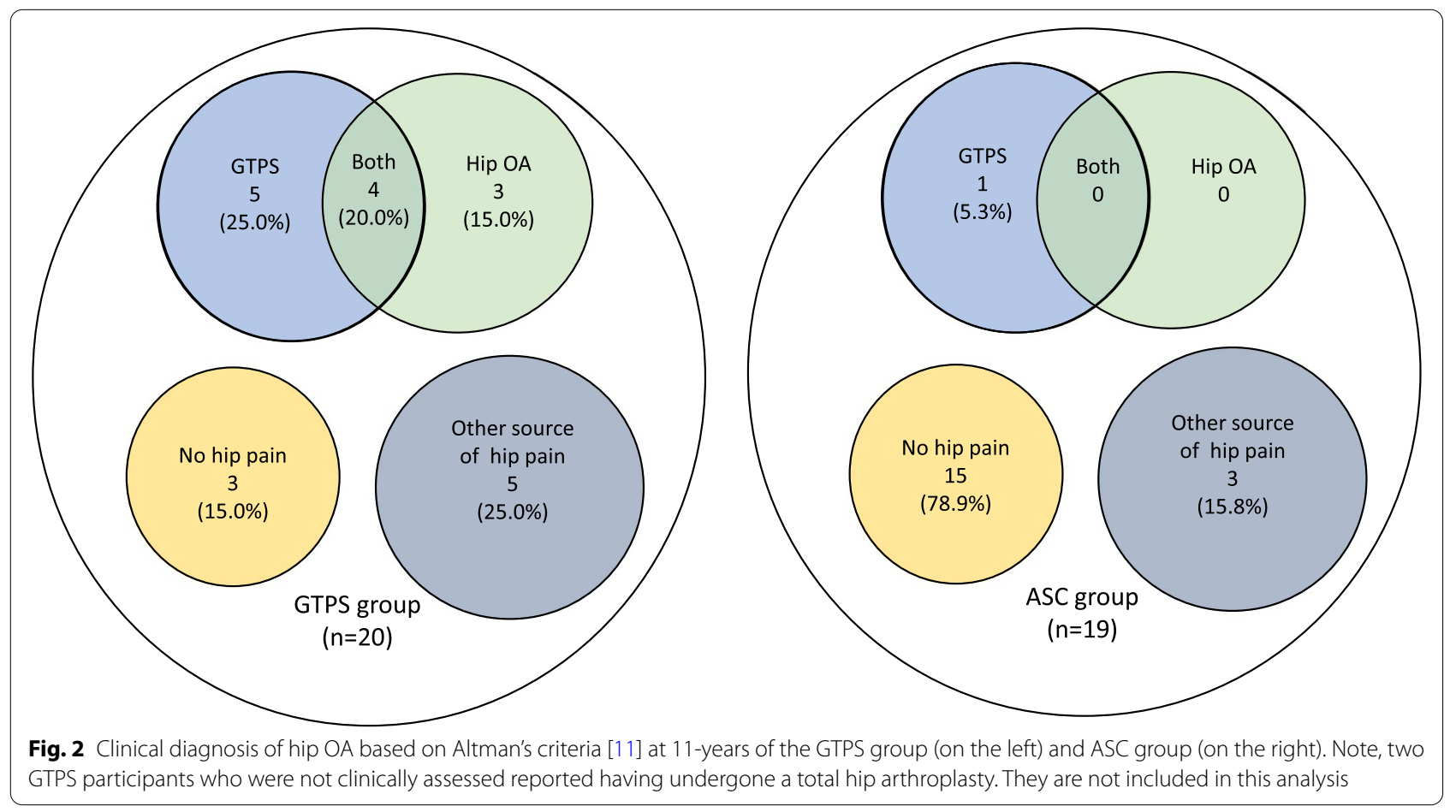


Table 3 Patient Reported Outcome Measures, Hip Strength and Gait Parameters Measured Across 11 years. Generalised linear models controlling for age and comorbidities provided estimated marginal means (SE) and 95\% ci at each time point

\begin{tabular}{|c|c|c|c|c|c|c|c|c|c|}
\hline \multirow[t]{3}{*}{ Outcome } & \multicolumn{9}{|c|}{ Estimated Marginal Means (SE) and $95 \% \mathrm{Cl}$ by Group and Assessment Time Point. Controlling for age and $\mathrm{FCl}^{\mathrm{b}}$} \\
\hline & \multicolumn{3}{|c|}{$\begin{array}{l}\text { Baseline } \\
\text { Age }=52.76, \mathrm{FCl}=1.96\end{array}$} & \multicolumn{3}{|c|}{$\begin{array}{l}\text { 12-month follow-up } \\
\mathrm{Age}=54.2, \mathrm{FCl}=1.73\end{array}$} & \multicolumn{3}{|c|}{$\begin{array}{l}\text { 11-year follow-up } \\
\mathrm{Age}=62.5 \mathrm{yrs}, \mathrm{FCl}=2.18\end{array}$} \\
\hline & $\begin{array}{l}\text { GTPS } \\
(n=31)\end{array}$ & $\begin{array}{l}\text { ASC } \\
(n=23)\end{array}$ & $\begin{array}{l}\text { Difference } \\
{[95 \% \mathrm{Cl}]}\end{array}$ & $\begin{array}{l}\text { GTPS } \\
(n=31)\end{array}$ & $\begin{array}{l}\text { ASC } \\
(n=21)\end{array}$ & $\begin{array}{l}\text { Difference } \\
{[95 \% \mathrm{Cl}]}\end{array}$ & $\begin{array}{l}\text { GTPS } \\
(n=24)\end{array}$ & $\begin{array}{l}\text { ASC } \\
(n=20)\end{array}$ & $\begin{array}{l}\text { Difference } \\
\text { [95\% Cl] }\end{array}$ \\
\hline $\begin{array}{l}\text { AQoL (utility } \\
0-1 \text { ) }\end{array}$ & $\begin{array}{l}0.78(0.02) \\
{[0.74,0.82]}\end{array}$ & $\begin{array}{l}0.89(0.02) \\
{[0.83,0.93]}\end{array}$ & $\begin{array}{l}-0.10^{\mathrm{a}} \\
{[-0.17,-0.03]}\end{array}$ & $\begin{array}{l}0.88(0.02) \\
{[0.84,0.93]}\end{array}$ & $\begin{array}{l}0.85(0.03) \\
{[0.792,0.90]}\end{array}$ & $\begin{array}{l}0.03 \\
{[-0.05,0.11]}\end{array}$ & $\begin{array}{l}0.84(0.02) \\
{[0.80,0.88]}\end{array}$ & $\begin{array}{l}0.87(0.02) \\
{[0.82,0.91]}\end{array}$ & $\begin{array}{l}-0.23 \\
{[-0.08,0.04]}\end{array}$ \\
\hline mHHS (0-91) & $\begin{array}{l}67.8(1.9) \\
{[64.0,71.6]}\end{array}$ & $\begin{array}{l}87.2(2.2) \\
{[82.7,91.7]}\end{array}$ & $\begin{array}{l}-19.4^{\mathrm{a}} \\
{[-25.6,-13.1]}\end{array}$ & $\begin{array}{l}77.1(1.6) \\
{[73.9,80.2]}\end{array}$ & $\begin{array}{l}82.8(1.9) \\
{[78.9,86.6]}\end{array}$ & $\begin{array}{l}-5.7^{\mathrm{a}} \\
{[-10.9,-0.47]}\end{array}$ & $\begin{array}{l}79.2(2.3) \\
{[74.6,83.8]}\end{array}$ & $\begin{array}{l}82.5(2.5) \\
{[77.5,87.6]}\end{array}$ & $\begin{array}{l}-3.3 \\
{[-10.3,3.7]}\end{array}$ \\
\hline \multirow[t]{2}{*}{ ODI (0-100) } & $\begin{array}{l}20.2(1.3) \\
{[17.5,22.9)}\end{array}$ & $\begin{array}{l}3.5(1.6)[0.3 \\
6.7)\end{array}$ & $\begin{array}{l}16.7^{\mathrm{a}} \\
{[12.3,21.1)}\end{array}$ & $\begin{array}{l}12.5(1.4)[9.6 \\
15.4)\end{array}$ & $\begin{array}{l}4.7(1.8) \\
{[1.1,8.3)}\end{array}$ & $\begin{array}{l}7.8^{\mathrm{a}} \\
{[3.0,12.7)}\end{array}$ & $\begin{array}{l}12.8(1.8)[9.2 \\
16.4)\end{array}$ & $\begin{array}{l}6.6(2.0)[2.7 \\
10.6)\end{array}$ & $\begin{array}{l}6.1^{\mathrm{a}} \\
{[0.7,11.6)}\end{array}$ \\
\hline & & & & & & & $n=20$ & $n=19$ & \\
\hline $\begin{array}{l}\text { Strength } \\
\text { (Hip Abd (N/ } \\
\left.\text { BM }^{\text {BMavg) }}\right)\end{array}$ & $\begin{array}{l}36.9(4.1) \\
{[28.9,44.9]}\end{array}$ & $\begin{array}{l}45.1(4.8) \\
{[35.7,54.4]}\end{array}$ & $\begin{array}{l}-8.2(4.3) \\
{[-16.6,0.24]}\end{array}$ & $\begin{array}{l}40.7(3.9) \\
{[33.0,48.4]}\end{array}$ & $\begin{array}{l}42.5(4.6) \\
{[33.4,51.6]}\end{array}$ & $\begin{array}{l}-1.8(4.2) \\
{[-10.1,6.5]}\end{array}$ & $\begin{array}{l}29.1(6.0) \\
{[17.4,40.8]}\end{array}$ & $\begin{array}{l}39.6(6.5) \\
{[26.8,52.5]}\end{array}$ & $\begin{array}{l}--10.5 \\
{[--21.2,0.2]}\end{array}$ \\
\hline $\begin{array}{l}\text { Strength } \\
(\text { Hip ER (N/ } \\
\left.\left.\text { BM }^{\text {BMavg }}\right)\right)\end{array}$ & $\begin{array}{l}17.1(1.5) \\
{[14.1,20.2]}\end{array}$ & $\begin{array}{l}18.8(1.8) \\
{[15.2,22.3]}\end{array}$ & $\begin{array}{l}--1.7(1.6) \\
{[-4.8,1.5]}\end{array}$ & $\begin{array}{l}18.7(1.5) \\
{[15.8,21.6]}\end{array}$ & $\begin{array}{l}19.2(1.7) \\
{[15.8,22.6]}\end{array}$ & $\begin{array}{l}-0.53(1.6) \\
{[-3.6,2.6]}\end{array}$ & $\begin{array}{l}18.9(3.5)^{c} \\
{[12.1,25.6]}\end{array}$ & $\begin{array}{l}21.2(3.5) \\
{[14.2,28.1]}\end{array}$ & $\begin{array}{l}-2.3(2.7) \\
{[-7.5,2.9]}\end{array}$ \\
\hline $\begin{array}{l}\text { TUG } \\
(\mathrm{sec})^{\mathrm{d}}\end{array}$ & $\begin{array}{l}9.3(0.40)^{d} \\
{[8.5,10.1]}\end{array}$ & $\begin{array}{l}8.6(0.43) \\
{[7.7,9.5]}\end{array}$ & $\begin{array}{l}0.7(0.63) \\
{[-0.6,1.9]}\end{array}$ & $\begin{array}{l}8.8(0.42)[8.0, \\
9.7]\end{array}$ & $\begin{array}{l}8.9(0.52)[7.8, \\
9.9]\end{array}$ & $\begin{array}{l}-0.09(0.71) \\
{[-1.5,1.3]}\end{array}$ & $\begin{array}{l}6.6(0.22)[6.2, \\
7.1]\end{array}$ & $\begin{array}{l}6.0(0.23)[5.5, \\
6.4]\end{array}$ & $\begin{array}{l}0.7^{\mathrm{a}} \\
{[0.01,1.3]}\end{array}$ \\
\hline $\begin{array}{l}\text { Gait Speed } \\
(\mathrm{m} / \mathrm{s})^{d}\end{array}$ & $\begin{array}{l}1.1(0.39)^{d} \\
{[1.0,1.2]}\end{array}$ & $\begin{array}{l}1.3(0.04)^{c} \\
{[1.3,1.4]}\end{array}$ & $\begin{array}{l}-0.1^{\mathrm{a}}(0.03) \\
{[-0.3,0.0]}\end{array}$ & $\begin{array}{l}1.3(0.03)^{\mathrm{c}} \\
{[1.2,1.3]}\end{array}$ & $\begin{array}{l}1.3(0.04) \\
{[1.2,1.3]}\end{array}$ & $\begin{array}{l}0.01 \\
{[-0.1,0.1]}\end{array}$ & $\begin{array}{l}1.8(0.06) \\
{[1.6,1.9]}\end{array}$ & $\begin{array}{l}1.9(0.06) \\
{[1.7,2.0]}\end{array}$ & $\begin{array}{l}-0.1 \\
{[-0.3,0.0]}\end{array}$ \\
\hline
\end{tabular}

a Indicates a statistically significant finding

$A Q o L$ Higher score indicates higher quality of life

$m H H S$ Higher score indicates higher function and less pain

Strength: Higher score indicates higher strength

Gait speed: Higher score in more desirable

Time up and go: lower score is more desirable.

${ }^{b}$ Baseline and 12-month data does not include those excluded from 11 year follow-up, but does include those lost to follow-up

c One participant requested this examination be ceased due to hip pain. §: Baseline TUG: GTPS $n=27$, Gait speed: GTPS, $n=26$, ASC, $n=22$. 12-month follow-up gait speed: GTPS $n=30$.

d Different instructions were inadvertently used at the 11-year follow-up than baseline.

in that group. While the participants who were not followed up were not statistically different from those who were (Additional file 2), we still controlled for age and co-morbidities thus reducing the risk of a type two error. The limited sample size may affect these data in relation to function. The only other long-term followup paper reports the quality of life and function of those with pain is lower than those without pain [5]. We did not undertake that analysis.

\section{Limitations}

We acknowledge several limitations within this project. Firstly, the 11-year follow-up diagnosis of hip OA was performed in the absence of an $x$-ray. The diagnosis of hip OA is more accurate when performed in combination with a radiographic examination [11]. However, we repeated the clinical examination using alternative criteria [13], with very similar results. Further, Kim et al (2015) demonstrated a potential inconsistency between clinical and radiographic diagnosis of early OA in the hip [36] meaning that imaging may have biased our results. In addition, we question whether it would be ethical to expose the participants to hip x-rays when it is not difficult to clinically diagnose symptomatic hip OA [13, 37]. We acknowledge that the use of ultra-sound and/or magnetic resonance imaging would have enhanced the diagnosis of GTPS. Secondly, while we had a small sample size, we achieved a high follow-up rate of 77\% (GTPS) and 87\% (ASC) after 11-years, further, our post-hoc power analysis indicates we had an adequately powered study for determining the risk of hip OA. Nonetheless the small sample size indicates that these results should be considered with caution. Thirdly, the 10mwt and TUG were inadvertently conducted differently at the 11-year follow-up compared to the baseline and 12-month follow-up as participants were asked to walk as fast as they could safely, while at the baseline and 12-month data points, participants were instructed to walk at a self-selected pace when completing 
these tests. Nevertheless, we can confidently compare between groups at each time point but not within the groups across the different follow-up periods. In addition, we only evaluated the original symptomatic leg, thus clinical tests that relied on both legs may have been compromised. Finally, we did not undertake reliability studies, however LB was trained and supervised by AF - who undertook the original study, and we used outcomes with published high inter-rater reliability.

\section{Conclusions}

This study demonstrates that many people with GTPS continue to experience hip pain (including due to GTPS) and appear to have a higher chance of developing hip OA after 11-years than a comparison group. These findings should be confirmed with a larger study. Clinicians involved in treating people with GTPS should be aware that over time their management strategies may need to change. Future studies should investigate biomechanical and somatosensory impairments and their effects on joint contact forces. Furthermore, investigations exploring effective long-term conservative management strategies are necessary to reduce the burden of GTPS, and the risk of developing hip OA.

\section{Abbreviations}

10mwt: 10 metre walk test; ASC: Asymptomatic control; AQoL: Assessment of Quality of Life; FCl: Functional Co-morbidity Index; GTPS: Greater Trochanteric Pain Syndrome; GT: Gluteal Tendon; kgf: kilogram x force; kgf/mMavg: (kilogram $x$ force)/metre BodyMassAverage. mHHS: Modified Harris Hip Score; m: metres; OA: Osteoarthritis; ODI: Oswestry Disability Index; TUG: Timed Up and Go; VISA-G: Victorian Institute of Sport - Gluteal.

\section{Supplementary Information}

The online version contains supplementary material available at https://doi. org/10.1186/s12891-021-04935-w.

\section{Additional file 1}

Additional file 2 .

\section{Acknowledgements}

We wish to acknowledge Professors Paul Smith, Jennie Scarvell and Jill Cook who were involved in the initial data collection. We would also like to acknowledge Assoc. Prof. Diana Perriman and Dr Andrew Woodward for their help with the statistics used in this study.

\section{Authors' contributions}

LB contributed to the design, collected, analysis and interpreted the participant data regarding clinical diagnosis and function. LB was a major contributor to the writing of the manuscript. JC contributed to design, collected, analysis and interpreted the participant data regarding clinical diagnosis. IK collected and interpreted the participant data regarding clinical diagnosis and function. AF undertook the design and conception of the study. AF supervised the collected and analysis of the participant data. AF interpreted the data and was a major contributor to the writing of the manuscript. All authors read and approved the final manuscript.

\section{Funding}

Dr Fearon and Dr Cookes' salaries were paid for by the University of Canberra. Mr Bicket was a student at the time of the research and received no funding. Mr Knott's salary was funded by Canberra Health Services.

\section{Availability of data and materials}

The University of Canberra is currently setting up a data repository platform within Mendeley. It is expected that this will be functional within the next six months. Subject to manuscript acceptance, at that point, the data from this study will be uploaded to that platform. Until that time the datasets used and/ or analysed during the current study available from the corresponding author on reasonable request.

\section{Declarations}

\section{Ethics approval and consent to participate}

This study was approved by the University of Canberra human research ethics committees (HREC: 20181528), all participants provided signed informed consent. Previous informed consent had been obtained from the participants at the baseline assessment for later follow-up, all participants reconsented for the 2019 follow-up assessment. Initial ethics approval was provided by the ACT Health HREC (HTH.7/07.663), and the Australian National University (HREC: 2007/0062). The research was undertaken in accordance with the Declaration of Helsinki.

\section{Consent for publication}

No identifiable data is presented in this publication.

\section{Competing interests}

None of the authors have any competing interests

\section{Author details}

${ }^{1}$ Faculty of Health, University of Canberra, 11 Kirinari St, Bruce, ACT 2617, Australia. ${ }^{2}$ Research Institute for Sport and Exercise, University of Canberra, 11 Kirinari St, Bruce, ACT 2617, Australia. ${ }^{3}$ Trauma and Orthopaedic Research Centre at the Canberra Hospital, Garren, ACT 2606, Australia. ${ }^{4}$ Canberra Health Services, 20 Guraguma St, Bruce 2617, Australia.

Received: 29 July 2021 Accepted: 3 December 2021

Published online: 20 December 2021

\section{References}

1. Fearon AM, Cook JL, Scarvell JM, Neeman T, Cormick W, Smith PN. Greater trochanteric pain syndrome negatively affects work, physical activity and quality of life: a case control study. J Arthroplasty. 2014;29(2):383-6.

2. Kong A, Van der Vliet A, Zadow S. MRI and US of gluteal tendinopathy in greater trochanteric pain syndrome. Eur Radiol. 2007;17(7):1772-83.

3. Long SS, Surrey DE, Nazarian LN. Sonography of greater trochanteric pain syndrome and the rarity of primary bursitis. Am J Roentgenol. 2013;201(5):1083-6.

4. Albers IS, Zwerver J, Diercks RL, Dekker JH, Van den Akker-Scheek I. Incidence and prevalence of lower extremity tendinopathy in a Dutch general practice population: a cross sectional study. BMC Musculoskelet Disord. 2016;17(1):16.

5. Lievense A, Bierma-Zeinstra S, Schouten B, Bohnen A, Verhaar J, Koes B. Prognosis of trochanteric pain in primary care. Br J Gen Pract. 2005;55(512):199-204.

6. Cates HE, Schmidt MA, Person RM. Incidental "rotator cuff tear of the hip" at primary total hip arthroplasty. Am J Orthop (Belle Mead NJ). 2010;39(3):131-3.

7. Howell G, Biggs R, Bourne R. Prevalence of abductor mechanism tears of the hips in patients with osteoarthritis. J Arthroplasty. 2001;16(1):121-3.

8. Shbeeb MI, Matteson EL. Trochanteric bursitis (greater trochanter pain syndrome). Mayo Clin Proc. 1996;71(6):565-9.

9. Ebert JR, Retheesh T, Mutreja R, Janes GC. The clinical, functional and biomechanical presentation of patients with symptomatic hip abductor tendon tears. Int J Sports Phys Ther. 2016;11(5):725. 
10. Fearon A, Neeman T, Smith P, Scarvell J, Cook J. Pain, not structural impairments may explain activity limitations in people with gluteal tendinopathy or hip osteoarthritis: A cross sectional study. Gait Posture. 2016:52:237-43

11. Altman R, Alarcon G, Appelrouth D, Bloch D, Borenstein D, Brandt K, et al. The American College of Rheumatology criteria for the classification and reporting of osteoarthritis of the hip. Arthritis Rheum. 1991;34(5):505-14.

12. Glyn-Jones $S$, Palmer A, Agricola R, Price A, Vincent $T$, Weinans $H$, et al. Osteoarthritis and Cartilage. 2015:386(9991):376-87.

13. Metcalfe D, Perry DC, Claireaux HA, Simel DL, Zogg CK, Costa ML. Does This Patient Have Hip Osteoarthritis?: The Rational Clinical Examination Systematic Review. JAMA. 2019;322(23):2323-33.

14. Hawthorne G, Richardson J, Osborne R. The Assessment of Quality of Life (AQoL) instrument: a psychometric measure of health-related quality of life. Qual Life Res. 1999;8(3):209-24.

15. Richardson J, Sinha K, lezzi A, Khan M. Modelling the utility of health states with the Assessment of Quality of Life (AQoL) 8D instrument: overview and utility scoring algorithm. Research Paper 63, Center for Health Economics. 2011.

16. Tijssen M, van Cingel R, van Melick N, de Visser E. Patient-Reported Outcome questionnaires for hip arthroscopy: a systematic review of the psychometric evidence. BMC Musculoskelet Disord. 2011;12(1):117.

17. Fairbank JC, Pynsent PB. The Oswestry disability index. Spine (Phila Pa 1976). 2000;25(22):2940-53.

18. Groll DL, To T, Bombardier C, Wright JG. The development of a comorbidity index with physical function as the outcome. J Clin Epidemiol. 2005;58(6):595-602.

19. Bazett-Jones DM, Cobb SC, Joshi MN, Cashin SE, Earl JE. Normalizing hip muscle strength: establishing body-size-independent measurements. Arch Phys Med Rehabil. 2011;92(1):76-82.

20. van Herk IEH, Arendzen JH, Rispens P. Ten-metre walk, with or without a turn? Clin Rehabil. 1998;12(1):30-5.

21. Kennedy DM, Stratford PW, Wessel J, Gollish JD, Penney D. Assessing stability and change of four performance measures: a longitudinal study evaluating outcome following total hip and knee arthroplasty. BMC Musculoskelet Disord. 2005;6:3.

22. Firth D. Bias reduction of maximum likelihood estimates. Biometrika. 1993;80(1):27-38

23. Puhr R, Heinze G, Nold M, Lusa L, Geroldinger A. Firth's logistic regression with rare events: accurate effect estimates and predictions? Stat Med. 2017;36(14):2302-17.

24. Venzon D, Moolgavkar S. A method for computing profile-likelihoodbased confidence intervals. J Appl Stat. 1988;37(1):87-94.

25. Christmas C, Crespo CJ, Franckowiak SC, Bathon JM, Bartlett SJ, Andersen RE. How common is hip pain among older adults. J Fam Pract. 2002:51(4):346-8.

26. Dagenais S, Garbedian S, Wai EK. Systematic review of the prevalence of radiographic primary hip osteoarthritis. Clin Orthop Relat Res. 2009;467(3):623.

27. Ibrahim M, Kartus J-T, Steigen SE, Olsen R, Meknas K. More tendon degeneration in patients with shoulder osteoarthritis. Knee Surg Sports Traumatol Arthrosc. 2019;27(1):267-75.

28. Meknas K, Johansen O, Steigen S, Olsen R, Jørgensen L, Kartus J. Could tendinosis be involved in osteoarthritis? Scand J Med Sci Sports. 2012;22(5):627-34.

29. Allison K, Wrigley TV, Vicenzino B, Bennell KL, Grimaldi A, Hodges PW. Kinematics and kinetics during walking in individuals with gluteal tendinopathy. Clin Biomech. 2016:32:56-63.

30. Zeni J Jr, Pozzi F, Abujaber S, Miller L. Relationship between physical impairments and movement patterns during gait in patients with endstage hip osteoarthritis. J Orthop Res. 2015;33(3):382-9.

31. Al-Hayani A. The functional anatomy of hip abductors. Folia Morphol (Praha). 2009;68(2):98-103.

32. Ferrer-Pena R, Calvo-Lobo C, La Touche R, Fernandez-Carnero J. Hip-Joint Posture and Movement Alterations Are Associated With High Interference of Pain in the Life of Patients With Greater Trochanteric Pain Syndrome. J Manipulative Physiol Ther. 2020;43(6):612-9.

33. Ferrer-Pena R, Moreno-Lopez M, Calvo-Lobo C, Lopez-de-UraldeVillanueva I, Fernandez-Carnero J. Relationship of Dynamic Balance Impairment with Pain-Related and Psychosocial Measures in Primary Care
Patients with Chronic Greater Trochanteric Pain Syndrome. Pain Med. 2019;20(4):810-7.

34. Fearon AM, Ganderton C, Scarvell JM, Smith PN, Neeman T, Nash C, et al. Development and validation of a VISA tendinopathy questionnaire for greater trochanteric pain syndrome, the VISA-G. Man Ther. 2015;20(6):805-13.

35. Berthelot J-M, Le Goff B, Maugars Y. The Hawthorne effect: stronger than the placebo effect? Joint Bone Spine. 2011;78(4):335-6.

36. Kim C, Nevitt MC, Niu J, Clancy MM, Lane NE, Link TM, et al. Association of hip pain with radiographic evidence of hip osteoarthritis: diagnostic test study. BMJ. 2015;351:h5983.

37. Murphy NJ, Eyles JP, Hunter DJ. Hip osteoarthritis: etiopathogenesis and implications for management. Adv Ther. 2016;33(11):1921-46.

\section{Publisher's Note}

Springer Nature remains neutral with regard to jurisdictional claims in published maps and institutional affiliations.
Ready to submit your research? Choose BMC and benefit from:

- fast, convenient online submission

- thorough peer review by experienced researchers in your field

- rapid publication on acceptance

- support for research data, including large and complex data types

- gold Open Access which fosters wider collaboration and increased citations

- maximum visibility for your research: over $100 \mathrm{M}$ website views per year

At BMC, research is always in progress.

Learn more biomedcentral.com/submissions 